H. M. Kulke

Röntgendiagnostik von Thoraxerkrankungen 

H. M. Kulke

\section{Röntgendiagnostik von Thoraxerkrankungen}

Von der Deskription zur Diagnose

unter Mitarbeit von

W. Burghardt, G. Ertl, M. Schmidt, B. Söller 
Prof. Dr. med. H. M. Kulke

Radiologe und Internist

Prof. für Röntgendiagnostik

Universitätsklinikum der Universität Würzburg

Oberdürrbacher Straße 6

97080 Würzburg

E-Mail: h-kulke-med-uni-wuerzburg@t-online.de

Das Buch enthält 166 Abbildungen und 12 Tabellen.

ISBN 978-3-11-031118-1

e-ISBN 978-3-11-031150-1

\section{Library of Congress Cataloging-in-Publication data}

A CIP catalog record for this book has been applied for at the Library of Congress.

\section{Bibliografische Information der Deutschen Nationalbibliothek}

Die Deutsche Nationalbibliothek verzeichnet diese Publikation in der Deutschen Nationalbibliografie; detaillierte bibliografische Daten sind im Internet über http://dnb.dnb.de abrufbar.

(C) 2013 Walter de Gruyter GmbH, Berlin/Boston

Der Verlag hat für die Wiedergabe aller in diesem Buch enthaltenen Informationen (Programme, Verfahren, Mengen, Dosierungen, Applikationen etc.) mit Autoren bzw. Herausgebern große Mühe darauf verwandt, diese Angaben genau entsprechend dem Wissensstand bei Fertigstellung des Werkes abzudrucken. Trotz sorgfältiger Manuskriptherstellung und Korrektur des Satzes können Fehler nicht ganz ausgeschlossen werden. Autoren bzw. Herausgeber und Verlag übernehmen infolgedessen keine Verantwortung und keine daraus folgende oder sonstige Haftung, die auf irgendeine Art aus der Benutzung der in dem Werk enthaltenen Informationen oder Teilen davon entsteht.

Die Wiedergabe der Gebrauchsnamen, Handelsnamen, Warenbezeichnungen und dergleichen in diesem Buch berechtigt nicht zu der Annahme, dass solche Namen ohne weiteres von jedermann benutzt werden dürfen. Vielmehr handelt es sich häufig um gesetzlich geschützte, eingetragene Warenzeichen, auch wenn sie nicht eigens als solche gekennzeichnet sind.

Druck und Bindung: Hubert \& Co., Göttingen

Einbandabbildung: Röntgenbild eines 42-jährigen Patienten. Im linken Oberfeld großes Bronchialkarzinom $(\varnothing \mathrm{ca} .7 \mathrm{~cm})$ mit zentraler Nekrose

(@) Gedruckt auf säurefreiem Papier

Printed in Germany

www.degruyter.com 


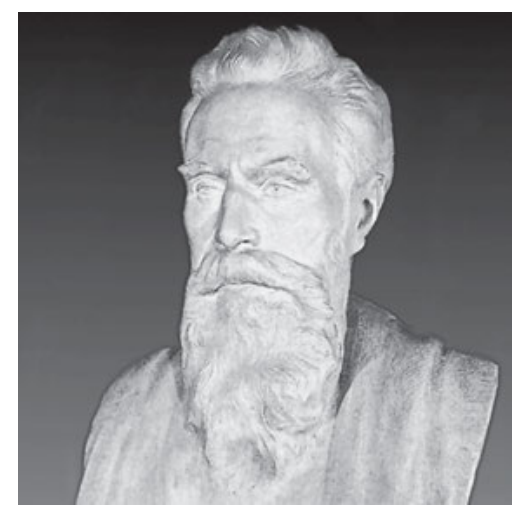

Wilhelm Conrad Röntgen

$1845-1923$

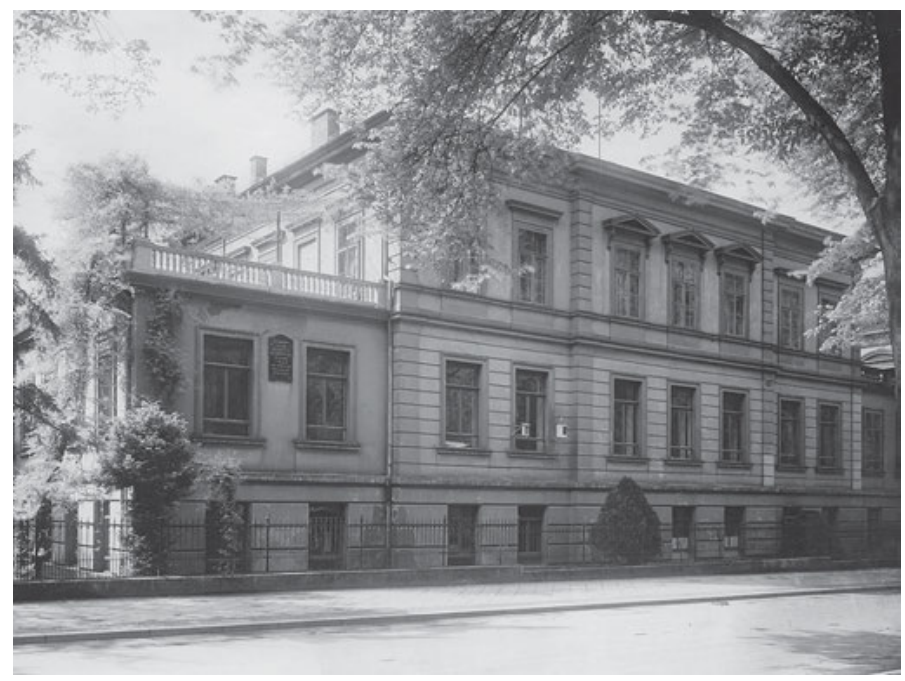

Das Physikalische Institut der Universität Würzburg. In diesem Gebäude entdeckte W. C. Röntgen am 8. November 1895 die nach ihm benannten Strahlen. 
